\title{
Long-term rotation and tillage effects on soil structure and crop yield
}

\author{
L.J. Munkholm, R.J. Heck, and B. Deen
}

This is a post-peer review, pre-copyedit version of an article published in Soil \& Tillage Research. The final authenticated version is available online at:

https://doi.org/10.1016/j.still.2012.02.007.

Suggested Citation: Munkholm, L.J., Heck, R.J., \& Deen, B. Long-term rotation and tillage effects on soil structure and crop yield. Soil Till Res 127, 85-91 (2013).

https://doi.org/10.1016/j.still.2012.02.007

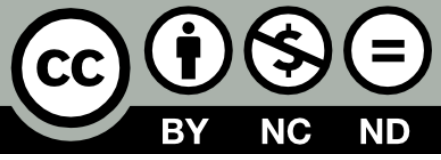




\section{Long-term rotation and tillage effects on soil structure and crop yield}

3 Lars J. Munkholm*1,2, Richard J. Heck ${ }^{2}$, Bill Deen ${ }^{3}$

$4 \quad{ }^{1 *}$ Aarhus University, Department of Agroecology, PO Box 50, DK-8830, Tjele, Denmark. E-mail:

$5 \quad$ lars.munkholm@agrsci.dk. Phone no. +45 89991768.

$6 \quad{ }^{2}$ University of Guelph, School of Environmental Sciences, Guelph, ON, N1G 2W1 Canada.

$7 \quad{ }^{3}$ University of Guelph, Department of Plant Agriculture, Guelph, ON, N1G 2W1 Canada.

$9 \quad *$ Corresponding author 


\section{Abstract}

12 Tillage and rotation are fundamental factors influencing soil quality and thus the sustainability of

13 cropping systems. Many studies have focused on the effects of either tillage or rotation, but few

14 have quantified the long term integrated effects of both. We studied the issue using a 30-year old 15 long-term rotation and tillage treatment experiment on a Canadian silt loam soil. Topsoil 16 measurements were carried out for three different rotations: R1 (C-C-C-C) continuous corn (Zea 17 mays L.), R6. (C-C-O(RC), B(RC)) corn, corn, oats (Avena fatua L.) and spring barley (Hordeum 18 vulgare L.) and R8, (C-C-S-S) corn, corn, soybean (Glycine max L.), soybean. A red clover 19 (Trifolium pretense L.) cover crop was under seeded in oats and spring barley in R6. In 2010, first 20 year corn was grown in R6 and R8. The tillage treatments included no tillage, NT and mouldboard 21 ploughing, MP. Topsoil structural quality was visually evaluated in early June and mid October.

22 Minimal disturbed soil cores collected in early June were used for X-ray CT scanning and to 23 quantify water content and porosity. Soil friability was determined on the soil samples using a drop 24 shatter test. Crop yield was determined and correlated to the soil quality estimates. We found 25 significant effect of both rotation and tillage on visual soil structure at both times of assessment. 26 Poor soil structure was found for NT except when combined with a diverse crop rotation (R6). The 27 soil core pore characteristics data also displayed a significant effect of tillage but only a weak 28 insignificant effect of rotation. The drop shatter results were in accordance with the visual 29 assessment data. Crop yield correlated significantly with the visual soil structure scores. We 30 conclude that a diverse crop rotation was needed for an optimal performance of NT for the studied 31 soil. 


\section{Keywords}

33 visual soil structure evaluation, soil quality, tillage, rotation, X-ray CT, yield. 


\section{1. Introduction}

35 Tillage and rotation are fundamental factors influencing soil quality, crop performance and thus

36 the sustainability of cropping systems. Conservation tillage per se is considered one of the most

37 effective management practices to obtain mutual benefits in terms of erosion control, carbon

38 sequestration and reduced input of energy and labour. However, maintaining crop yields is a

39 challenge when adopting conservation tillage in many traditional cereal-based cropping systems

40 (Carter et al., 1994; Meyer-Aurich 2006; Morris et al., 2010). Decreased soil physical quality, in

41 terms of excessive compaction of the untilled topsoil, is regarded as one of the primary reasons for

42 yield reductions (e.g. Carter et al., 1991; Ball et al., 1994). This is especially problematic on

43 weakly-structured soils in humid temperate climates (Munkholm et al., 2003). Many have

44 suggested the use of controlled traffic and stimulated biological activity to mitigate the problem

45 (Ehlers and Claupein, 1994; Munkholm et al., 2003). The latter is stimulated through the input of

46 crop residues and the use of diverse rotations and cover crops - all such factors are included in the

47 concept of conservation agriculture (CA), strongly promoted by FAO (www.fao.org/ag/ca). The

48 CA concept is supported by numerous studies which usually include a limited number of factors.

49 There is, however a shortage of studies, in which the long-term integrated effect of conservation,

50 tillage, rotation and cover crops on soil quality have been evaluated.

51 Assessment of soil structure is challenging because soil is a very heterogeneous and complex

52 medium. Visual soil evaluation methods have in recent years become a widespread tool for the

53 integrative evaluation of soil structure as highlighted in this special issue. For topsoil structure

54 evaluation, a number of methods are available such as the spade methods: VESS, Visual

55 Evaluation of Soil Structure (Ball et al., 2007) and VSA, Visual Soil Assessment method

56 (Shepherd, 2009) as well as the "le profil cultural" profile method (Manichon, 1987). In this study 
57 we applied the VESS method because it is takes account of a range of crucial properties (soil

58 strength, porosity and roots and biological activity), integrates over a rather large volume, is fast

59 and easy to use and integrates the evaluation of different aspects into a single number ranging from

601 (friable) to 5 (very compact). The numeric results, from the VESS test, allow statistical analysis

61 of management effects and exploration of linear correlations to other factors, such as crop yield or

62 quantitative soil physical properties. Visual soil evaluation methods are by nature, qualitative and

63 operator dependent. A visual key in combination with text guide was developed to minimize the

64 subjectivity when performing the VESS test. However, visual methods must be regarded as

65 complementary to quantitative methods. In this study the VESS test was supplemented with

66 quantification of porosity, soil friability, soil strength and detailed soil pore characteristics based

67 on X-ray CT scanning imagery.

68 The objective of this study was to evaluate the cumulative effects of tillage and selected rotations

69 on soil structure using the long-term rotation-tillage experiment at Elora Research Station (Meyer-

70 Aurich et al. 2006). We hypothesized a positive effect of diverse rotation (including cover crop)

71 on soil quality - especially under no tillage. A secondary objective was to link topsoil structure

72 assessment to crop yield. We expected a positive correlation between crop yield and topsoil quality.

\section{2. Materials and methods}

74

$75 \quad 2.1$ The experiment

76 Samples were taken from the long-term rotation and tillage trial (initiated in 1980) at the University

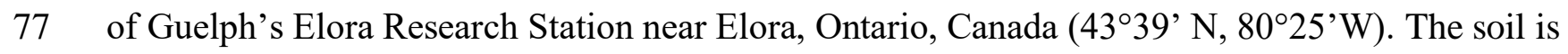


mapped as Woolwich silt loam and classified as a Grey Brown Luvisol (CSSC, 1998) or Albic

79 Luvisol (WRB, 2006). The particulate size distribution is on average: 16, 44, 40 and $2.13{\mathrm{~g} 100 \mathrm{~g}^{-}}^{-}$

$80{ }^{1}$ of clay, silt, sand and organic carbon, respectively. The 30 year average rainfall (1970-2000) was

$81920 \mathrm{~mm}$, and the average monthly temperatures for January, April and July are $-7.6,5.9$ and $19.7^{\circ} \mathrm{C}$,

82 respectively (Table 1 ). The 2010 growing season had monthly temperatures similar to long term

83 averages. Although annual precipitation in 2010 was lower than long term averages, rainfall

84 received during the 2010 April-September growing season exceeded long term average

85 precipitation and distribution was very good.

Table 1 around here

88 The experimental design is a randomized split plot with four replicates. The main plot treatment

89 is rotation and the plot treatment is tillage. Seven four-course rotations are included in the trial. In

90 this study we used rotation R1,(C-C-C-C) continuous corn (Zea mays L.), rotation R6, (C-C-O(RC),

$91 \mathrm{~B}(\mathrm{RC})$ ) corn, corn, oats (Avena fatua L.) and spring barley (Hordeum vulgare L.) and rotation R8,

92 (C-C-S-S) corn, corn, soybean (Glycine max L.), soybean. A red clover (Trifolium pretense L.)

93 cover crop was underseeded in oats and spring barley in R6. In 2010, first year corn was grown in

94 R6 and R8. The tillage treatments included no tillage (NT) and conventional tillage with

95 mouldboard ploughing (MP). Mouldboard ploughing $(20 \mathrm{~cm})$ was carried out on November 18

96 2009. Secondary tillage in MP consisted of two passes of a field cultivator and packer within 1

97 day of crop seeding. The tillage plots are $7 \times 17 \mathrm{~m}$ and 8 rows of corn were sown in each of the

98 studied plots on May 7 2010. The corn crop was harvested at full maturity on October 19 and the 99 yield was recorded. 


\subsection{Visual evaluation of soil structure}

101 Topsoil structural quality was visually evaluated according to the Visual Soil Structure Evaluation

102 (VESS) method described by Ball et al. (2007) and further refined by Guimaraes et al. (2011). The

103 topsoil $(0-20 \mathrm{~cm})$ is evaluated according to aggregation, porosity and root growth and graded on a

104 scale from Sq1 to Sq5 where 1 is best. Two assessments were carried out per plot in R1, R6 and

105 R8, i.e. 48 observation points. The soil was sampled in the centre of the plot between rows 2 and

1063 and rows 6 and 7 to avoid traffic zones. The evaluation was carried out on June 42010 when the

107 corn was in the 6 leaf tip stage and repeated just before harvest on October 18 2010. The average

108 gravimetric water content was $26 \%$ and $29 \%$, respectively at testing in June and October. This

109 corresponds to a matric potential around field water capacity at assessment according to soil water

110 retention data from the Elora site (Parkin, unpublished data).

\section{2.3. Penetration resistance}

112 Penetration resistance was measured, at approximately field capacity, with a RIMIK cone

113 penetrometer (Agridry Rimik, Toowoomba, Queensland, Australia) to a depth of $50 \mathrm{~cm}$ on May

11421 2010. All measurements employed a $20.27 \mathrm{~mm}$ diameter, 30 ${ }^{\circ}$ semi-angle cone. Penetration

115 resistance was recorded at each $25 \mathrm{~mm}$ increment. Five determinations were made per tillage plot 116 in all the studied rotations, i.e. 2(tillage) x 3(rotations) x 4(blocks) x 5(replicates) $=120$ determinations.

\subsection{Soil core sampling}

119 Two minimally disturbed soil cores $(\varnothing=6.4 \mathrm{~cm}$, height $=8.0 \mathrm{~cm})$ were taken at $10-20 \mathrm{~cm}$ depth in 120 R1 and R6 on May 28 2010. In all, 32 samples were taken. The samples were taken at the same 
121 location as for VESS test. Immediately after sampling, the samples were stored in a refrigerator at

$1225^{\circ} \mathrm{C}$ until $\mathrm{CT}$ scanning. The samples were also stored in the refrigerator between X-ray CT

123 scanning and the drop shatter test. The CT images from two samples were lost and data analyses

124 were, therefore, carried out on a total of 30 samples. Samples were weighed before CT scanning

125 and the drop shatter test, (field moist) condition and in air-dry condition after drop shatter and in oven

126 dry condition $\left(105^{\circ} \mathrm{C}, 24 \mathrm{~h}\right)$ after sieving. This allowed us to calculate total porosity and air-filled

127 porosity at sampling, $\varepsilon_{\mathrm{a}}$, as well as bulk density when assuming a particle density of $2.65 \mathrm{~g} \mathrm{~cm}^{-3}$.

\subsection{Drop shatter test}

130 Soil fragmentation behaviour was evaluated by a drop shatter test modified from the methods

131 described by Hadas and Wolf (1984) and Schjønning et al. (2002). The field sampled undisturbed 132 cores were gently pressed out of the tubes and dropped from $2.0 \mathrm{~m}$ height onto a concrete floor. The

133 soil was subsequently air-dried and passed through a nest of sieves with the openings of 19, 9.2, 4, 2

134 and $1 \mathrm{~mm}$. The amount of material in each size class was recorded. Based on the aggregate size 135 distribution data, the geometric mean diameter (GMD) and the approximate specific surface area $\left(\mathrm{m}^{2}\right.$ $\left.136 \mathrm{~kg}^{-1}\right)$ (Hadas and Wolf, 1983) were calculated.

139 The top $40 \mathrm{~mm}$ of the soil core samples were scanned using an EVS (now GE Medical, London,

140 Canada) microCT scanner, model MS8X-130. The samples were scanned at $120 \mathrm{kV}, 170 \mathrm{~mA}$ and 141 with a 3500 millisecond integration time, generating an axial sequence of X-ray attenuation 
142 imagery. For each soil sample, a region of interest (ROI) of 36m x 36mm x $36 \mathrm{~mm}$, extended

143 isometrically from the centroid of the image. The final reconstructed image had voxel size of 60

$144 \mu \mathrm{m}$. Please consult Munkholm et al. (2011) for more details on the scanning procedure and image

145 reconstruction. The open source software programme ImageJ was used for binary thresholding and

146 image analysis (Rasband, 2005). Binary imaging was carried out using the standardized and

147 automated thresholding procedure developed by Elliott and Heck (2007) and as detailed by

148 Munkholm et al. (2011). General pore characteristics in the 3D images were generated for each

149 ROI using the ImageJ 3D object counter plug-in (Bolte and Cordelires, 2006). This plug-in

150 determines total void volume $\left(\mathrm{pixel}^{3}\right)$, mean void volume and number of pores. In this study, a

151 minimum pore volume filter of 3 voxels was used. A skeleton reconstruction was also performed

152 for each sample to determine branching of the pores, average length of the pores and maximum

153 pore length. In this study the plug-in provided by BoneJ (Doube et al., 2010) was used outlined by

154 Munkholm et al. (2011). This skeletonised binary stack was then put through the analyze skeleton

155 plug-in within the BoneJ plug-in. This provided a summary of number, length (mean, maximum

156 and total) and junction of branches in each ROI.

\section{$158 \quad 2.7$ Statistical analysis}

159 All statistical analyses were carried out using SAS (Version 9.2, SAS Institute, Cary, NC) (SAS,

160 2005). We used PROC INSIGHT to test data for normality. The pore characteristics derived from

161 X-ray CT imagery were log-transformed to yield normality. All other data were best fitted by a

162 normal distribution. Averages were calculated for each plot and used in the calculation of mean 
163 and standard error. The averages were used as input in general linear models for test of treatment

164 effects. For this purpose we used PROC GLM in SAS.

165

166 3. Results

$168 \quad 3.1$ Visual soil structure evaluation, penetration resistance and crop yield

169 Significant effects of both tillage and rotation were found for the VESS Sq scores (Figure 1). There

170 was a strong effect of tillage $(\mathrm{MP}<\mathrm{NT})$ at both times of assessment (i.e. $\mathrm{P}<0.001$ and 0.002 for the

171 tillage effect at early and late season assessment, respectively). The average Sq scores increased

172 for both tillage treatments from June to October that is from 1.5 to 1.9 for MP and from 2.2 to 2.4

173 for NT. This means that the difference between tillage treatments decreased slightly from, $0.7 \mathrm{Sq}$

174 units in May to $0.5 \mathrm{Sq}$ units in October. The effect of rotation was in both cases significant at

$175 \mathrm{P}=0.05$ level and the lowest Sq scores was found for the diverse rotation, R6 in comparison with

176 the continuous corn (R1) or corn-soybean rotations (R8). The mean Sq score for R6 was

177 approximately 1.5 at both times of assessment whereas the Sq scores for R1 and R8 increased from

178 c. 2.0 in June to c. 2.4 in October. No significant interactions, between tillage and rotation, were

179 observed at any time of assessment. However, there was almost a significant interaction between

180 tillage and rotation for the June sampling $(\mathrm{P}=0.10)$. Highest values were recorded for the $\mathrm{R} 1-\mathrm{NT}$

181 treatment with a Sq score of 2.8 in October and lowest for R6-MP where Sq=1.3 at both times of 182 assessment. 
184 The penetration resistance data revealed significant effect of treatments in the topsoil at 5-20 cm

185 depth (Figure 2). No tillage produced higher penetration resistances than the MP treatment. The 186 highest values in the topsoil was recorded for R1-NT (max. 1.5 MPa) and lowest for R6-MP (max. 187 1.1 MPa). Strong effect of tillage was also found for the penetration resistance data when averaged 188 across $0-20 \mathrm{~cm}$ and $10-20 \mathrm{~cm}$ depth (Table 2). Notice, that the interaction between tillage and 189 rotation was almost significant $(\mathrm{P}=0.08)$ for the $10-20 \mathrm{~cm}$ data. Smallest difference between MP 190 and NT was recorded for R8 and largest for R1. There was no significant difference between the 191 treatments below $20 \mathrm{~cm}$ depth.

194 The corn yield was, in general, high (i.e. 90-120 hkg ha-1) and there were significant effects of 195 tillage, rotation and interaction between tillage and rotation (Table 2). The MP treatment produced 196 higher yields than NT - on average 109 and $104 \mathrm{hkg} \mathrm{ha}^{-1}$ for MP and NT, respectively. Larger 197 differences were obtained between the rotations, i.e. 96, 117 and 107 for R1, R6 and R8, 198 respectively. Notice that for R6 there was no significant difference in yield between MP and NT 199 whereas this was found for both R1 and R8 (i.e. c. $10 \mathrm{hkg} \mathrm{ha}^{-1}$ higher yields were found for MP). 
204 Bulk density, BD, at 10-20 cm depth differed markedly between tillage treatments (i.e. 1.46 and

$2051.28 \mathrm{~g} \mathrm{~cm}^{-3}$ for NT and MP, respectively) (Table 3). There was no significant effect of rotation or 206 interaction between rotation and tillage. However, there was a slight tendency to lower BD for R6 207 than for $\mathrm{R} 1(\mathrm{P}=0.15)$. The water content at sampling was on average $24 \mathrm{~g} 100 \mathrm{~g}^{-1}$. The drop shatter 208 test revealed significant effects of both tillage and rotation when expressed as surface area 209 produced. Almost significant effects $(\mathrm{P}=0.07)$ were also found when expressed as GMD (Table 3). 210 A larger surface area (i.e. smaller fragments) was produced for R6 vs. R1 and for MP vs. NT. The 211 largest surface area $\left(1.11 \mathrm{~m}^{2} \mathrm{~kg}^{-1}\right)$ was produced for R6-MP and lowest $\left(0.53 \mathrm{~m}^{2} \mathrm{~kg}^{-1}\right)$ for R1-NT.

212 The total porosity data was a mirror image of the BD results with significantly higher values 213 obtained for MP than NT (Figure 3a). The air-filled porosity at sampling results followed in line 214 with those for total porosity, i.e. MP>NT and no significant effect of rotation (Figure 3b). The MP 215 treatment had an average air-filled pore space at sampling (i.e. around field capacity) of $20.3 \mathrm{~m}^{3}$ $216 \mathrm{~m}^{-3}$ and NT $10.8 \mathrm{~m}^{3} \mathrm{~m}^{-3}$.

Table 3 and figure 3 around here

\subsection{Soil pore characteristics from microCT imagery}

221 The void volume identified in the microCT imagery, Por $\mathrm{CT}$, varied between 2.4 and $8.2 \mathrm{~m}^{3} \mathrm{~m}^{-3}$ for 222 the different treatments (Figure 3c). There was only a significant effect of tillage on Por ${ }_{\mathrm{CT}}$ $223(\mathrm{MP}>\mathrm{NT})$. The surface area results displayed similar trends as the Por ${ }_{\mathrm{CT}}$ results. Markedly higher 224 average values were obtained for MP than for NT (i.e. 3.4 and $1.4 \mathrm{~cm}^{2} \mathrm{~cm}^{-3}$, respectively) (Figure $2254 a)$. The number of pores showed a geometric mean of 71 per $\mathrm{cm}^{3}$ and this parameter was not 
226 sensitive to management (Figure 4b). For the data obtained on the skeletonised images (Figure 4c,

$227 \mathrm{~d}$, e) the geometric mean values were 117,279 and 198 per $\mathrm{cm}^{3}$ for junctions, branches and end 228 points, respectively. Higher values were in general obtained for MP than for NT although the 229 differences were only significant for junctions and branches (Figure 4).

Figure 4 around here

231 4. Discussion

\section{4.1. Management effects on physical soil quality}

233 The VESS results confirmed our hypothesis of a positive effect of diverse rotation and cover crops

234 on soil quality - especially under no tillage. The poorest structure was observed for the R1-NT 235 treatment in October $(\mathrm{Sq}=2.8)$ and best for R6-MP in May and October $(\mathrm{Sq}=1.3)$. It has to be 236 emphasized that all treatment averages were characterized as either $\operatorname{good}(\mathrm{Sq}=1-2)$ or fair $(\mathrm{Sq}=2-$

237 3) according to the threshold values suggested by Ball et al. (2007). Therefore, the soil was 238 assessed as favourable to crop production in all treatments. However, poor soil structures $(\mathrm{Sq}>3)$

239 were found in some individual R1-NT plots with Sq 3.8 as the highest recorded. A good soil 240 structure (i.e. Sq scores 1-2) was recorded for R6-MP, R6-NT at both times of sampling and for 241 R1-MP and R8-MP for the May sampling. Our results are in good agreement with previous visual 242 assessments from the trial (Mueller et al., 2009b) when applying other visual methods. They also 243 found a positive effect of tillage on topsoil structure and showed a better structure for continuous 244 alfalfa than for continuous corn. 
245 The quantitative soil core and penetration resistance data supported the VESS results in terms of a 246 clear effect of tillage. That is, the lowest penetration resistance and highest air-filled and total 247 porosity were found for MP in the topsoil layer $(0-20 \mathrm{~cm})$. The soil core data were taken in the 248 zone with most pronounced differences between tillage treatments according to the penetration 249 resistance results (Figure 2). Soil core data showed, in most cases, a weak and insignificant effect 250 of rotation. The drop shatter test, in contrast to the other examinations, showed a significant effect 251 of rotation when data were expressed as surface area produced. However, the general trend was 252 similar to the VESS results with R6 having more favourable physical properties than R1. The 253 VESS results were linearly correlated to the soil pore data and showed the best correlation to $\varepsilon_{\mathrm{a}}$, 254 air-filled porosity at sampling $\left(\mathrm{R}^{2}=0.59 * * *\right)$. Significant negative linear correlations were also 255 found to $\log$ porosity CT imagery $\left(\mathrm{R}^{2}=0.49^{* *}\right)$, total porosity $\left(\mathrm{R}^{2}=0.47 * *\right), \log$ number of 256 junctions $\left(\mathrm{R}^{2}=0.30 *\right)$ and there was almost significant negative correlation to log number of 257 branches $\left(\mathrm{R}^{2}=0.24\right)$. Visible macroporosity is one of the key parameters evaluated when applying 258 the VESS test and our results confirmed a strong influence of macroporosity on the VESS scores. 259 Apparently, pore complexity, quantified by number of junctions and branches, also influenced the 260 VESS scores, i.e. better scores for soil soils with a more complex macropore organization.

261 Result from the drop shatter test yields information on friability (Munkholm, 2011). Friability has 262 been proposed as an indicator of the suitability of a given soil for no tillage (Macks et al., 1996). 263 Our data indicate that the diverse rotation R6 promoted best suitability for no-tillage.

264 It is noticeable, that topsoil structural quality generally decreased from June till October for R1 265 and R8 and not R6. The largest decrease was found for MP (i.e. the Sq scores increased by c. 0.5 266 and 0.2 for MP and NT, respectively). Our study clearly suggests that growing corn per se may 
267 not improve topsoil structural quality. Introducing a double crop of rye between two crops of corn 268 may result in improved soil quality as shown by Liesch et al. (2011).

269 To summarize, our results indicate that the diverse R6 rotation resulted in a good topsoil structure 270 irrespective of tillage method. Thus, an optimal topsoil structure was achieved through the 271 combination of a diverse rotation and no tillage. For continuous corn (R1) and corn-soybean (R8)

272 poorer soil structure was observed especially for NT. This is in correspondence with results from

273 numerous other studies (e.g. Braim et al., 1992; Ball et al., 2007; Munkholm et al., 2003, 2008).

\subsection{Corn yield and correlation to soil structure}

276 The corn yield was very high in $2010\left(107 \mathrm{hkg} \mathrm{ha}^{-1}\right)$ in comparison with the average for first year

277 corn of c. $82 \mathrm{hkg} \mathrm{ha}^{-1}$ observed for the years 1982-2001 (Meyer-Aurich, 2006) and c. $79 \mathrm{hkg} \mathrm{ha}^{-1}$

278 found in 2005 (Mueller et al., 2009b). The high yield level was a result of close to optimal growing 279 conditions during the cropping season, i.e. a warm summer without marked periods of too dry or 280 wet conditions. Despite this, we observed a significant effect of intensive tillage, rotation and the 281 interaction between tillage and rotation on crop yield. This is in agreement with previous 282 observations from the experiment (Meyer-Aurich, 2006; Mueller et al., 2009b). Interestingly, the 283 relative differences were much larger in 2010 than for 1982-2001 and 2005. The yield benefit of a 284 diverse rotation (R6) as compared to continuous corn no till (R1-NT) was $28 \%$ and $13 \%$ for 2010 285 and 1982-2001, respectively. Yield benefits from growing first-year corn in a corn-soybean 286 rotation (R8) relative to continuous corn R1-NT were 7-11\%, 10-14\% and 10-23\%, for 1982-2001 287 (Meyer-Aurich et al., 2006), 2005 (Mueller et al., 2009b) and 2010 (this study), respectively. For 
288 R8, the largest yield benefit was found for the ploughed treatment in 2010 and this corresponds

289 with previous results from the experimented (Meyer-Aurich et al., 2006; Mueller et al., 2009b).

290 Our experimental results indicate a rather good correlation between topsoil structure and crop

291 yield as shown in Figure 5. Corn yields decreased linearly with increasing VESS Sq values

$292\left(\mathrm{R}^{2}=0.35^{* *}\right)$. Weaker correlations were found withthe quantitative soil physical properties (data not

293 shown). The relatively good agreement between visual methods and crop yield is in agreement

294 with previous studies (Mueller et al., 2009a; Mueller et al. (this issue); Giarola et al. (this issue).

295 In general quantitative physical data were not very sensitive to rotation effect. Apparently, the

296 VESS method was better able to detect differences between rotations - most likely because a range

297 of crucial factors were taken into account (e.g. root growth) and because a relatively large volume

298 of soil was evaluated.

300 The profound effect of rotation and especially tillage on yield was rathersurprising when 301 considering the excellent growing conditions in 2010 when soil water content was expected to be

302 within the least limiting water range for root growth during almost the entire growing season.

303 Structure affects crop yield through a complex of root-based mechanisms including those that are

304 moisture related. Many examples of this exist. For example a negative effect of mechanical

305 impedance on leaf growth and nitrogen uptake have been found even when nutrients and water

306 were in plentiful supply (Young et al., 1997; Bingham et al., 2010). Also under conditions with no

307 nutrient and water restrictions, Munkholm et al. (2008) found impeded early season growth for

308 winter wheat under no tillage as compared to ploughing. They related the difference to poorer 309 structural quality (more compact) under no tillage. Enhanced plant root exudation with increasing 
310 soil mechanical impedance has been widely reported (Barber and Gunn, 1974; Boeuf-Tremblay et

311 al. 1995; Iijima et al., 2000). Finally, soil structure effects on root characteristics may alter plant

312 growth through root biochemical signaling affects on above ground processes as discussed in the

313 comprehensive review by Passioura (2002).

\section{5. Conclusions}

315 - The visual soil structure evaluation supported the hypothesized positive effect of diverse 316 rotation (including cover crop) on soil quality - especially under no tillage. For no tillage, 317 optimal soil structure was only found in diverse R6 rotation that included a cover crop.

318 - The quantitative physical properties confirmed the positive effect of intensive tillage on 319 soil structure but showed in general a weak and insignificant effect of rotation.

320 - Crop yield correlated significantly with the visual soil structure scores.

321 We conclude that a diverse crop rotation was needed for an optimal performance of NT for the 322 studied soil. Therefore our study supports the idea behind the conservation agriculture concept, 323 i.e. sustainability is promoted when conservation tillage is combined with crop rotation, cover $324 \quad$ crops and residue management. 


\section{Acknowledgements}

327 This work was supported by the OECD Co-operative Research Programme Fellowship, Trade and 328 Agriculture (TAD/PROG) and the Danish ministry for Food, Agriculture and Fisheries through 329 the Sustainable Plant Production Systems to Mitigate Global Warming (CoolCrop) Project. The 330 technical assistance from Henk Wichers and Tatiana Rittl is gratefully acknowledged.

\section{$331 \quad$ References}

332 Ball,B.C., Lang,R.W., Robertson,E.A.G., Franklin,M.F., 1994. Crop performance and soil conditions on imperfectly drained loams after 20-25 years of conventional tillage or direct drilling. Soil Tillage Res. 31, 97-118.

Ball, B.C., Batey, T., Munkholm, L.J., 2007. Field assessment of soil structural quality - a development of the Peerlkamp test. Soil Use Manage. 23, 329-337.

337 Barber, D.A., Gunn, K.B., 1974. The effect of mechanical forces on the exudation of organic substances by the roots of cereal plants grown under sterile conditions. New Phytol. 73, 3945.

Bingham,I.J., Bengough,A.G., Rees,R.M., 2010. Soil compaction-N interactions in barley: Root growth and tissue composition. Soil Tillage Res. 106, 241-246.

342 Boeuf-Tremblay, V., Plantureux,S., Guckert, A., 1995. Influence of mechanical impedance on root exudation of maize seedlings at two developmental stages. Plant Soil 172, 279-287. 
344 Bolte, S., Cordelières, F. P., 2006. A guided tour into subcellular colocalization analysis in light 345 microscopy, J. Microscopy. 224, 213-232.

346 Braim, M.A., Chaney, K., Hodgson, D.R., 1992. Effects of simplified cultivation on the growth 347 and yield of spring barley on a sandy loam soil .2. Soil physical-properties and root-growth 348 - root -shoot relationships, inflow rates of nitrogen - water-use. Soil Tillage Res. 22, 173349187.

350 Carter, M.R., 1991. Evaluation of shallow tillage for spring cereals on a fine sandy loam. 2. Soil 351 physical, chemical and biological properties. Soil Tillage Res. 21, 37-52.

352 Carter, M.R., 1994. A review of conservation tillage strategies for humid temperate regions. 353 Soil .Tillage Res. 31, 289-301.

354 CSSC, 1998. The Canadian System of Soil Classification, third ed.

355 Doube, M., Kłosowski, M.M., Arganda-Carreras, I., Cordelières, F, Dougherty, R.P., Jackson, J., 356 Schmid, B., Hutchinson, J.R., Shefelbine, S.J., 2010. BoneJ: free and extensible bone 357 image analysis in ImageJ, Bone, 47, 1076-1079.

358 Ehlers, W., Claupein, W., 1994. Approaches toward conservation tillage in Germany. In: Carter, M.R. (Ed.), Conservation Tillage in Temperate Agroecosystems, Lewis Publishers, pp. 141-165.

361 Elliot, T.R., Heck, R.J., 2007. A comparison of optical and X-ray CT technique for void analysis 362 in soil thin section. Geoderma 141, 60-70. 
363 Elliot, T.R., Heck, R.J., 2007. A comparison of optical and X-ray CT technique for void analysis 364 in soil thin section. Geoderma 141, 60-70.

365 FAO, 2011. Conservation agriculture. Avaiable at http://www.fao.org/ag/ca/ (accessed 31. $366 \quad$ August 2011).

367 Giarola,N.B., da Silva,A.P., Tormena,C.A., Guimaraes,R.L., Ball, B.C., On the visual evaluation 368 of soil structure: The Brazilian experience in oxisols under no-tillage. Soil Tillage Res. 369 (submitted to this issue).

370 Guimarães, R.M.L., Ball, B.C., Tormena, C.A., 2011. Improvements in the visual evaluation of 371 soil structure. Soil Use Manage. 27, 395-403.

372 Hadas, A., Wolf, D., 1983. Energy efficiency in tilling dry clod-forming soils. Soil Tillage Res. 373 3, 47-59.

374 Hadas, A. and Wolf, D., 1984. Refinement and re-evaluation of the drop-shatter soil 375 fragmentation method. Soil Tillage Res. 4: 237-249.

376 Iijima, M., Griffiths, B, Bengough, G., 2000. Sloughing of cap cells and carbon exudation from 377

378 Liesch, A.M., Krueger, E.S., Ochsner, T.E., 2011. Soil structure and physical properties under 379 rye-corn silage double-cropping systems. Soil Sci.Soc.Am.J. 75, 1307-1314. management history and suitability for direct drilling. Aust. J. Soil Res. 34, 343-360. 
Manichon, H. 1987. Observation morphologique de l'état structural et mise en evidence d'effects du compactage des horizons travaillés. In: Monnier, G., Goss, M.J. (eds.). Soil compaction and regeneration. Balkema, Rotterdam, the Netherlands, pp. 35-52.

Meteorological Services Canada. 2011. Canadian climate normals: 1971-2000.Available at www.climate.weatheroffice.ec.gc.ca/climate_normals (accessed 30. Aug. 2011). Environment Canada, Ottawa, ON.

Meyer-Aurich, A., Janovicek, K., Deen, W., Weersink, A., 2006. Impact of tillage and rotation on yield and economic performance in corn-based cropping systems. Agron. J., 98, 12041212.

Morris, N.L., Miller, P.C.H., Orson, J.H., Froud-Williams, R.J., 2005. The adoption of noninversion tillage systems in the United Kingdom and the agronomic impact on soil, crops and the environment--A review. Soil Tillage Res. 108, 1-15.

Mueller, L., Kay, B.D., Hu, C., Li, Y., Schindler, U., Behrendt, A., Shepherd, T.G., Ball, B.C., 2009a. Visual assessment of soil structure: Evaluation of methodologies on sites in Canada, China and Germany: Part I: Comparing visual methods and linking them with soil physical data and grain yield of cereals. Soil Tillage Res. 103, 178-187.

Mueller,L., Kay,B.D., Deen,B., Hu,C., Zhang,Y., Wolff,M., Eulenstein,F., Schindler,U., 2009 b. Visual assessment of soil structure: Part II. Implications of tillage, rotation and traffic on sites in Canada, China and Germany. Soil Tillage Res. 103, 188-196. 
Mueller, L., Schindler, U., Ball, B.C., Munkholm, L.J., Hennings, V., Smolentseva, E., Rukhovic, O., Lukin, S., Hu, C., Shepherd, G. Evaluation of Soil Structure in the Framework of an Overall Soil Quality Rating. Soil Tillage Res. (submitted to this issue).

Munkholm, L.J., 2011. Soil friability: A review of the concept, assessment and effects of soil properties and management. Geoderma (In Press).

Munkholm, L.J., Heck, R., Deen, B. Soil friability assessment from micro-CT derived images on undisturbed field moist soil cores Geoderma (Submitted).

Munkholm, L.J., Schjønning, P., Rasmussen, K.J., Tanderup,K., 2003. Spatial and temporal effects of direct drilling on soil structure in the seedling environment. Soil Tillage Res. 71, 163-173.

Munkholm, L.J., Hansen, E.M., Olesen, J.E., 2008. The effect of tillage intensity on soil structure and winter wheat root/shoot growth. Soil Use Manage. 24, 392-400.

Passioura, J.B., 2002. 'Soil conditions and plant growth'. Plant Cell Env. 25, 311-318.

Rasband, W., 2005. ImageJ. National Institute of Health, Bethesda MD.

SAS Institute, 2005. SAS Institute, SAS/STAT ${ }^{\mathrm{TM}}$ Software: Language reference and concepts Release 9.1.3, SAS Institute, Cary, NC.

Schjønning, P., Elmholt, S., Munkholm, L.J., Debosz, K., 2002. Soil quality aspects of humid sandy loams as influenced by organic and conventional long-term management. Agric. Ecosyst. Env. 88, 195-214. 
421 Shepherd, T.G., 2009. Visual soil assessment. Volume 1. Field guide for pastoral grazing and 422 cropping on flat and rolling country. Second edition. Horizons Regional Council, 423 Palmerston North, New Zealand, 119p.

424 WRB, 2006. World reference base for soil resources 2006. Food and Agriculture Organization of $425 \quad$ United Nations, Rome.

426 Young, I.M., Montagu, K., Conroy,J., Bengough, A.G., 1997. Mechanical impedance of root 427 growth directly reduces leaf elongation rates of cereals. New Phytol. 135:613-619. 
Table 1- Average monthly temperature and monthly total precipitation, Elora, Ontario, Canada for 2008, 2009, 2010.

\begin{tabular}{lrrrrrrrr}
\hline & \multicolumn{4}{c}{ Temperature $\left({ }^{\circ} \mathrm{C}\right)$} & \multicolumn{5}{c}{ Precipitation $(\mathrm{mm})$} \\
\cline { 2 - 9 } & 2008 & 2009 & 2010 & 30 -yr Av.* & 2008 & 2009 & 2010 & 30 -yr Av.* \\
\hline January & -4.7 & -11.7 & -7.2 & -7.6 & 98.5 & 66.1 & 27.2 & 56.4 \\
February & -8.6 & -6.1 & -5.8 & -6.9 & 57.4 & 82 & 24.4 & 50.8 \\
March & -5.2 & -0.7 & 2.2 & -1.3 & 85.5 & 72.7 & 41.3 & 72.1 \\
April & 7.5 & 6.1 & 8.7 & 5.9 & 64.6 & 106.2 & 47.5 & 78.3 \\
May & 9.8 & 11.4 & 13.8 & 12.3 & 86.1 & 79.3 & 99.9 & 79.9 \\
June & 17.6 & 15.8 & 16.8 & 16.9 & 81.6 & 69.2 & 184.1 & 76 \\
July & 19.1 & 16.5 & 20.2 & 19.7 & 131.3 & 79.5 & 89.4 & 88.5 \\
August & 17.2 & 17.8 & 19.4 & 18.6 & 120.7 & 92.1 & 12.1 & 95.9 \\
September & 14.8 & 14.5 & 14.0 & 14.1 & 119.3 & 53.7 & 117.8 & 92.1 \\
October & 7.2 & 6.8 & 8.3 & 7.9 & 68.4 & 91.5 & 52.6 & 69.2 \\
November & 0.7 & 4.6 & 3.0 & 2.4 & 103.1 & 37.3 & 50.8 & 86.3 \\
December & -5.5 & -4.5 & -6.1 & -4 & 100.4 & 65.8 & 21.1 & 77.7 \\
\hline
\end{tabular}

*Source: Meteorological Services Canada, 2011. 
Table 2. Effect of rotation and tillage on penetration resistance (May sampling) and yield of the corn crop. R1-MP: continuous corn, mouldboard ploughed, R1-NT: continuous corn, no tillage; R6-MP: R6. Diverse rotation, mouldboard ploughed; R6-NT: Diverse rotation, no tillage; R8MP: corn-soybean rotation, mouldboard ploughed; R8-NT: corn-soybean rotation, no tillage.

\begin{tabular}{|c|c|c|c|}
\hline \multirow[t]{2}{*}{ Treatment } & \multicolumn{2}{|c|}{ Penetration resistance } & \multirow[t]{2}{*}{ Crop yield } \\
\hline & $0-20 \mathrm{~cm}$ & $10-20 \mathrm{~cm}$ & \\
\hline & \multicolumn{2}{|c|}{$\mathrm{MPa}$} & $\mathrm{Hkg} \mathrm{ha}^{-1}$ \\
\hline R1-NT & $1,1 \mathrm{a}$ & $1.5 \mathrm{a}$ & $91 d$ \\
\hline R1-MP & $0.8 \mathrm{~b}$ & $1.0 \mathrm{c}$ & $101 \mathrm{c}$ \\
\hline R6-NT & $1.0 \mathrm{a}$ & $1.3 \mathrm{~b}$ & $119 \mathrm{a}$ \\
\hline R6-MP & $0.7 \mathrm{~b}$ & $0.9 \mathrm{c}$ & $115 \mathrm{ab}$ \\
\hline R8-NT & $1.0 \mathrm{a}$ & $1.3 \mathrm{~b}$ & $101 \mathrm{c}$ \\
\hline R8-MP & $0.8 \mathrm{~b}$ & $1.1 \mathrm{c}$ & $112 \mathrm{~b}$ \\
\hline Rotation & NS & NS & $* *(\mathrm{p}=0.005)$ \\
\hline Tillage & $* * *(p<0.0001)$ & $* * *(\mathrm{p}<0.0002)$ & $* *(\mathrm{p}=0.002)$ \\
\hline Rotation*Tillage & NS & $\mathrm{NS}(\mathrm{p}=0.08)$ & $* *(\mathrm{p}=0.002)$ \\
\hline
\end{tabular}


Table 3. Bulk density, water content and drop shatter data for the core samples taken late May 2010. R1-MP: continuous corn, mouldboard ploughed, R1-NT: continuous corn, no tillage; R6-MP: R6. Diverse rotation, mouldboard ploughed; R6-NT: Diverse rotation, no tillage.

\begin{tabular}{lllll}
\hline Treatment & Soil core & \multicolumn{2}{l}{ Drop shatter test } \\
\hline & Bulk density & Water content & GMD & Surface area \\
& & at sampling & & \\
\hline & $\mathrm{g} \mathrm{cm}^{-3}$ & $\mathrm{~g} 100 \mathrm{~g}^{-1}$ & $\mathrm{~mm}$ & $\mathrm{~m}^{2} \mathrm{~kg}^{-1}$ \\
R1-NT & $1.48 \mathrm{a}$ & $23.9 \mathrm{a}$ & $14.6 \mathrm{a}$ & $0.53 \mathrm{c}$ \\
R1-MP & $1.31 \mathrm{~b}$ & $24.6 \mathrm{a}$ & $10.6 \mathrm{ab}$ & $0.73 \mathrm{bc}$ \\
R6-NT & $1.43 \mathrm{a}$ & $23.7 \mathrm{a}$ & $8.2 \mathrm{~b}$ & $0.83 \mathrm{~b}$ \\
R6-MP & $1.25 \mathrm{~b}$ & $23.8 \mathrm{a}$ & $6.5 \mathrm{~b}$ & $1.11 \mathrm{a}$ \\
\hline Rotation & $\mathrm{NS}$ & $\mathrm{NS}$ & $\mathrm{NS}(\mathrm{p}=0.07)$ & $*(\mathrm{p}=0.04)$ \\
Tillage & $* * *(\mathrm{p}=0.0009)$ & $\mathrm{NS}$ & $\mathrm{NS}$ & $*(\mathrm{p}=0.02)$ \\
Rotation*Tillage & $\mathrm{NS}$ & $\mathrm{NS}$ & $\mathrm{NS}$ & $\mathrm{NS}$ \\
\hline
\end{tabular}




\section{Figure captions}

Figure 1.Visual Soil Structure Evaluation Sq score for 0-20 cm depth at the beginning and the end

of the 2010 growing season. Corn was grown in all treatments. Bars indicate $+/-1$ standard error of mean. Figures with the same letter within each time of sampling are not significantly different at $\mathrm{P}<0.05$ level. R1: continuous corn; R6: diverse rotation; R8: corn-soybean rotation; MP: mouldboard ploughed; NT: no tillage.

Figure 2. Penetration resistance determined in the field at a water content around field capacity at 0-45 cm depth. R1-MP: continuous corn, mouldboard ploughed, R1-NT: continuous corn, no tillage; R6-MP: R6. Diverse rotation, mouldboard ploughed; R6-NT: Diverse rotation, no tillage; R8-MP: corn-soybean rotation, mouldboard ploughed; R8-NT: corn-soybean rotation, no tillage. Bars indicate $+/-1$ standard error of mean.

Figure 3. Total porosity, air-filled porosity at sampling, $\varepsilon_{\mathrm{a}}$, on soil cores and porosity determined from the CT imagery. Bars indicate $+/-1$ standard error of mean. Figures with the same letter for each parameter are not significantly different at $\mathrm{P}<0.05$ level. $\mathrm{R} 1$ : continuous corn; R6: diverse rotation; MP: mouldboard ploughed; NT: no tillage.

Figure 4. Pore characteristics from CT imagery. Bars indicate $+/-1$ standard error of mean. Figures with the same letter for each parameter are not significantly different at $\mathrm{P}<0.05$ level. R1: continuous corn; R6: diverse rotation; MP: mouldboard ploughed; NT: no tillage.

Figure 5. Correlation between corn yield and Sq score (June assessment). 


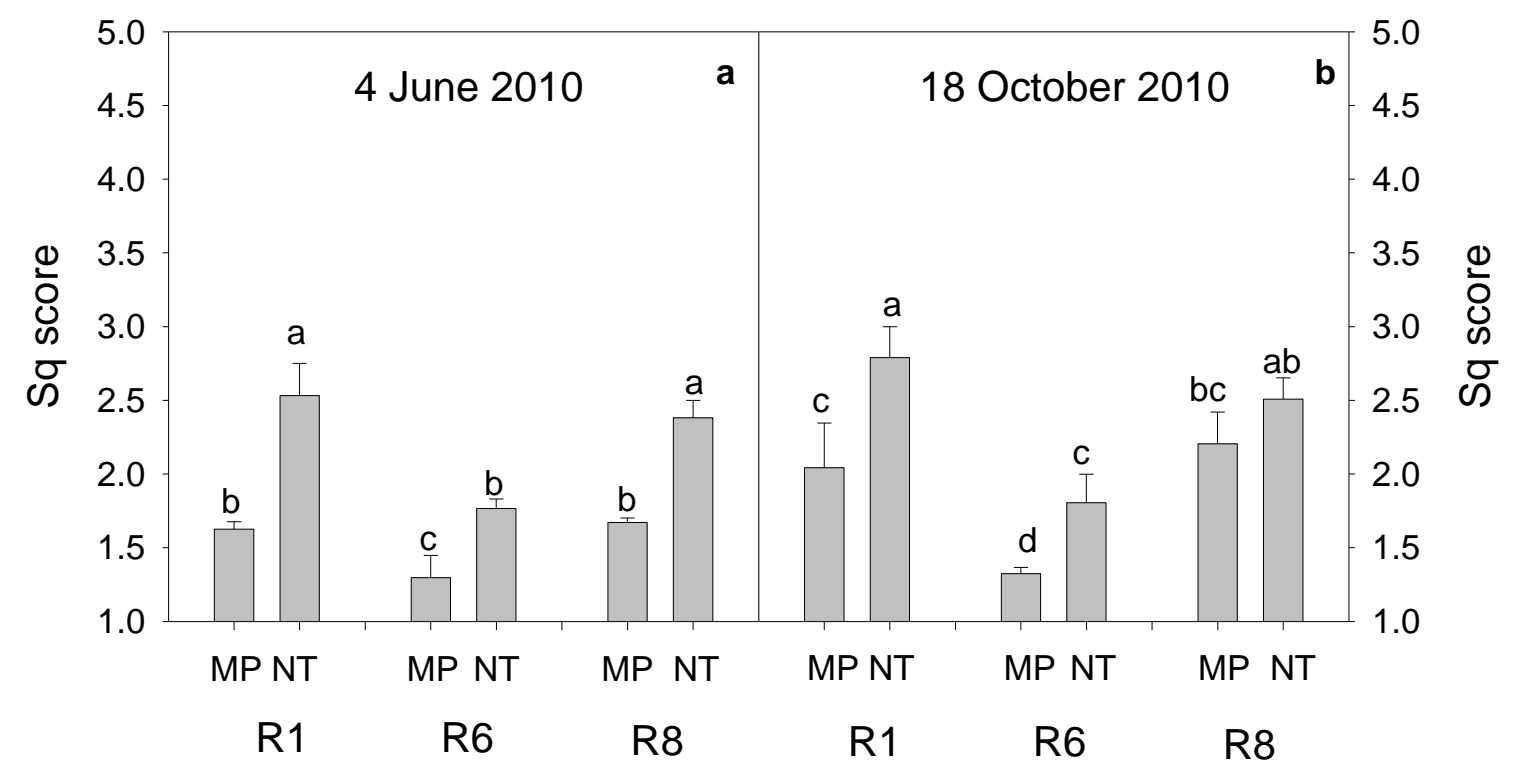

Figure 1.Visual Soil Structure Evaluation Sq score for 0-20 cm depth at the beginning and the end of the 2010 growing season. Corn was grown in all treatments. Bars indicate $+/-1$ standard error of mean. Figures with the same letter within each time of sampling are not significantly different at $\mathrm{P}<0.05$ level. R1: continuous corn; R6: diverse rotation; R8: corn-soybean rotation; MP: mouldboard ploughed; NT: no tillage. 


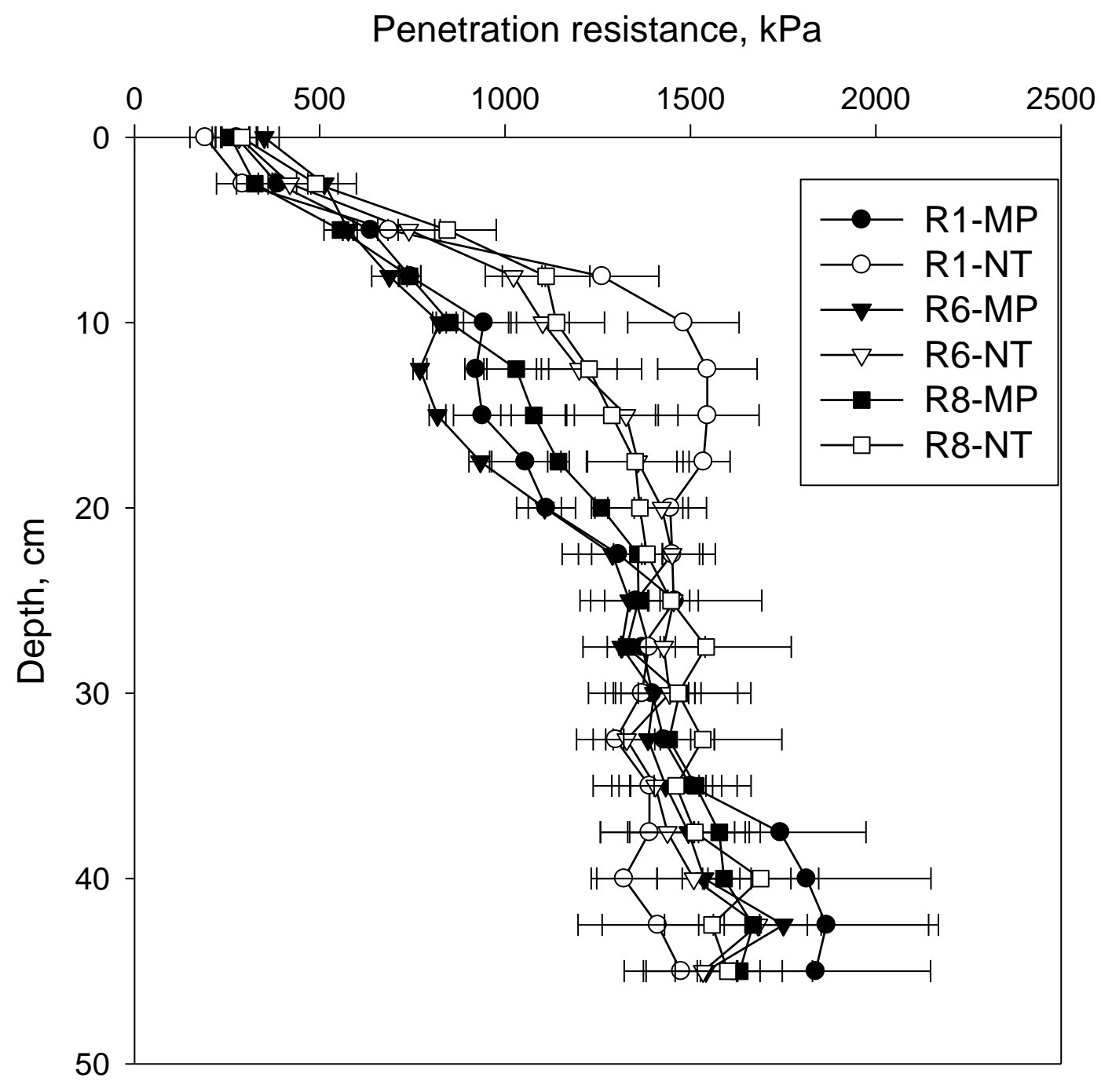

Figure 2. Penetration resistance determined in the field at a water content around field capacity at 0-45 cm depth. R1-MP: continuous corn, mouldboard ploughed, R1-NT: continuous corn, no tillage; R6-MP: R6. Diverse rotation, mouldboard ploughed; R6-NT: Diverse rotation, no tillage; R8-MP: corn-soybean rotation, mouldboard ploughed; R8-NT: corn-soybean rotation, no tillage. Bars indicate $+/-1$ standard error of mean. 


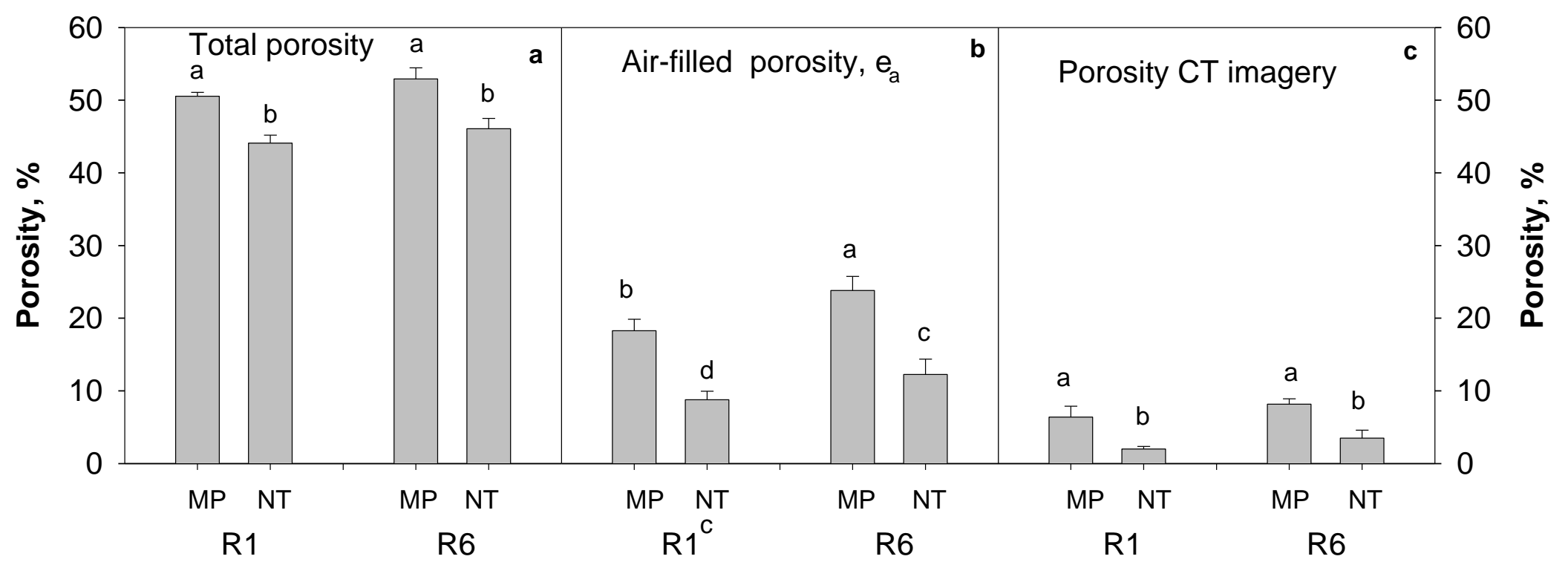

Figure 3. Total porosity, air-filled porosity at sampling, $\varepsilon_{\mathrm{a}}$, on soil cores and porosity determined from the CT imagery. Bars indicate +/-1 standard error of mean. Figures with the same letter for each parameter are not significantly different at $\mathrm{P}<0.05$ level.

R1: continuous corn; R6: diverse rotation; MP: mouldboard ploughed; NT: no tillage. 


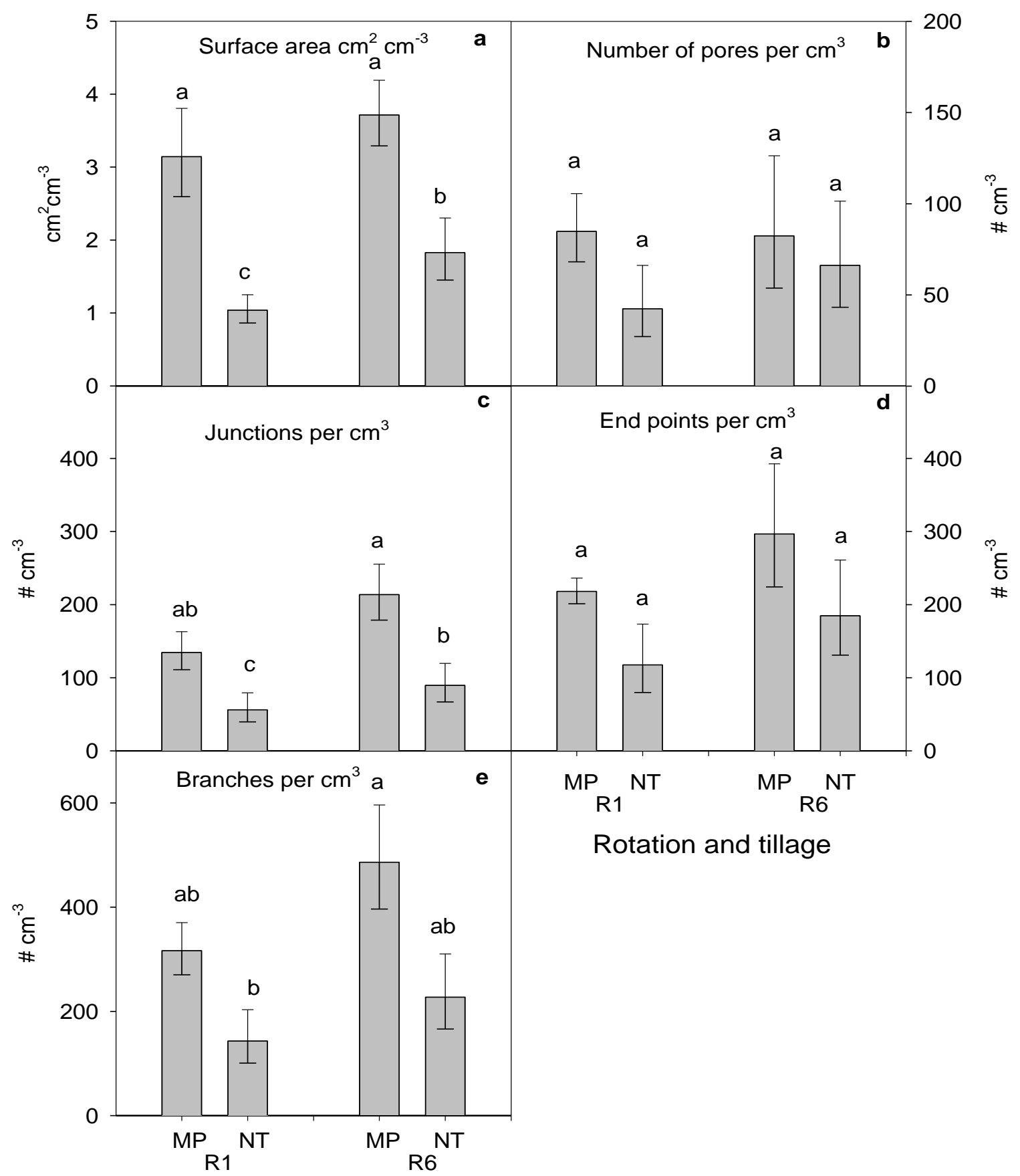

Rotation and tillage 
Figure 4. Pore characteristics from CT imagery. Bars indicate $+/-1$ standard error of mean. Figures with the same letter for each parameter are not significantly different at $\mathrm{P}<0.05$ level. $\mathrm{R} 1$ : continuous corn; R6: diverse rotation; MP: mouldboard ploughed; NT: no tillage. 


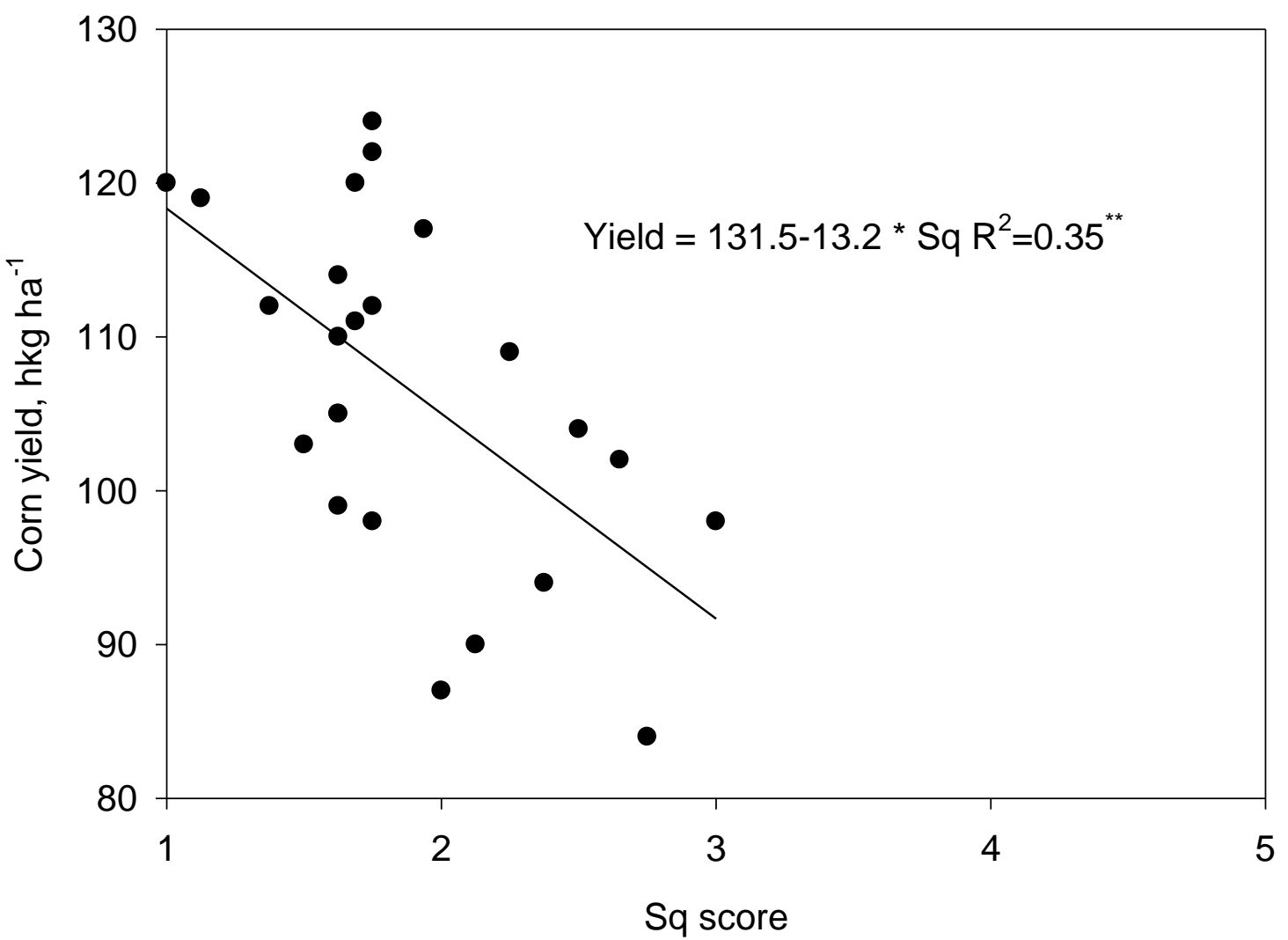

Figure 5. Correlation between corn yield and Sq score (June assessment). 